\title{
Influence of Internal Combustion Engine Parameters on Gas Leakage through the Piston Rings Area
}

\author{
Waleed Momani ${ }^{1,2^{*}}$ \\ ${ }^{1}$ Mechanical Engineering Department, Faculty of Engineering, King Abdulaziz University, Rabigh, KSA \\ ${ }^{2}$ Department of Mechanical Engineering, FET, Al-Balqa Applied University, Amman, Jordon \\ Email: momaniwaleed@yahoo.com
}

How to cite this paper: Momani, W. (2017) Influence of Internal Combustion Engine Parameters on Gas Leakage through the Piston Rings Area. Modern Mechanical Engineering, 7, 27-33. https://doi.org/10.4236/mme.2017.71003

Received: December 4, 2016

Accepted: February 25, 2017

Published: February 28, 2017

Copyright $\odot 2017$ by author and Scientific Research Publishing Inc. This work is licensed under the Creative Commons Attribution International License (CC BY 4.0).

http://creativecommons.org/licenses/by/4.0/

(c) (i) Open Access

\begin{abstract}
In this work, the influence of internal combustion engine parameters (cylinder-piston clearance, piston head height, the first segment position, gap of the first piston ring and gap of the second piston ring, piston rings' axial clearance, intake valve debit coefficient) gas leakage from the combustion chamber through the piston rings' area was investigated. This influence was studied by making an initial forming operation over gas leakage in the analyzed area.
\end{abstract}

\section{Keywords}

Piston, Clearance, Combustion Engine, Cylinder-Piston, Piston Rings, Chamber, Gas Leakage

\section{Introduction}

The piston ring assembly in an internal combustion engine works as a labyrinth to the combustion gas chamber and to the inferior crankcase. The spaces between the segments are used for gas expansion and elongating the circuit's length of gases. These reduced sections produce a higher flowing resistance. The labyrinth effect of the piston rings assembly is shown by the variations of gas pressure over the piston ring area.

Several volumes, supposed as constant (for the analysis procedure), make this labyrinth. The volumes are connected through some conduits, the sections of which might be constituted by: gaps of pistons, ring radial clearances of these, piston ring axial clearance and cylinder-piston clearance.

It must be considered that, during a working cycle, the average flexible pressure (radial internal pressure) of the piston ring is sufficient to maintain the ${ }^{\star}$ KSA on leave from Faculty of Engineering Technology, Al-Balqa Applied University, Jordan. 
contact between the lateral face of the piston ring and the cylinder surface. This last parameter can be neglected, as long as, behind the segment the gas pressure from the piston ring grooves works [1].

It is real that the flow area of the analyzed sections is not constant because of the segments' axial movement in the grooves. Two opposite areas are always connected through the gap of piston ring between them, and then through the space created by the momentary piston ring position into its groove (depending on axial clearance a and radial clearance $\mathrm{r}$ ).

The segment transition from the superior ring groove flank to the inferior one is not instantaneous; it takes 20 - 60 crankshaft revolutions. So, it is very important to establish the instantaneous piston ring position in its groove depending on the rotation angle of the crankshaft.

\section{Basic Elements}

In order to complete the analysis, a piston with two compression piston rings and a lubrication piston ring was considered [2]. The spaces between the piston, cylinder, segments and the bottom of the piston rings groove, constitute different areas of the labyrinth, hindering gas leakage from the combustion chamber (CC) to the crankcase (Figure 1). The labyrinth is shown as follows:

- 5 regions from 1 to 5 can be defined;

- Region 1 is defined by the volume placed over the first piston ring between the piston and the cylinder to the upper part of the piston's head (plan A);

- Region 2 is defined by the volume between the internal diameter of the first segment $\left(D_{i s}\right)$ and the outer diameter of the ring groove of the piston;

- Region 5 is defined by the volume between the second compression ring, the stripping ring, the piston and the cylinder (this volume is constantly connected to the crankcase);

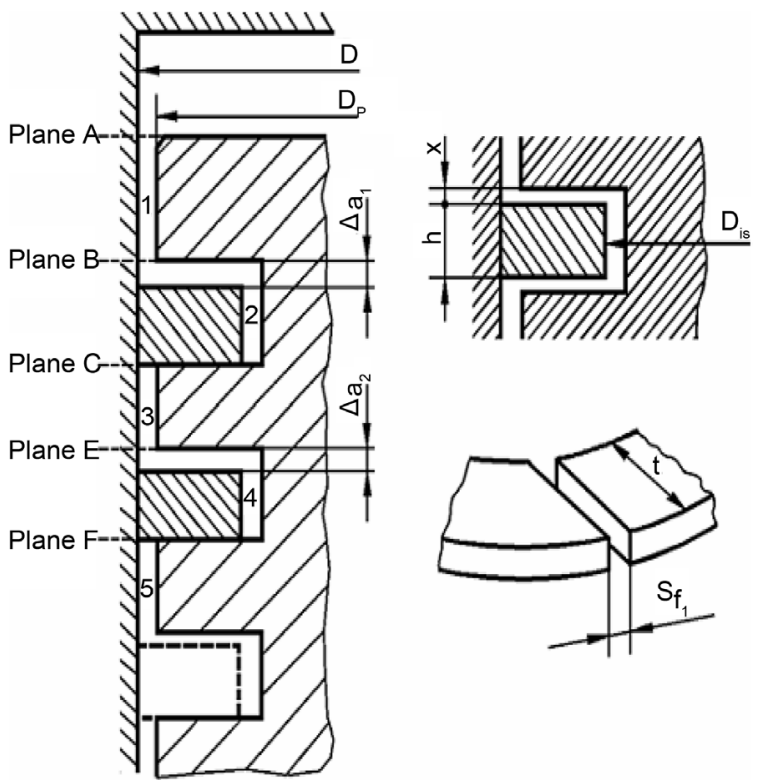

Figure 1. The geometric model used. 
- Plane A is a fictitious plane separating the combustion chamber from region 1;

- Plane $\mathrm{B}$ is situated to the superior flank of the first piston ring groove;

- Plane C and plane F are situated to the inferior flank of the first and the second piston ring groove;

- Plane $\mathrm{E}$ is to the superior flank of the second piston ring groove.

The forming operation of gas escape along the piston ring area was made using some assumptions: the gas pressure of region 1 and that of the combustion chamber are equal the gas pressure of region 5 is the same as the gas pressure of the crankcase. It was also supposed that different volumes remain constant during a working cycle.

The gas leakage (from the combustion chamber to the crankcase) over the analyzed area was considered rolling and isotherm. The flowing area caused by the piston-cylinder clearance was supposed to be circular, even if the clearance would not be uniformly distributed over the whole circumference during the piston's secondary movement. This assumption is justified on one hand by the short time of tilting (about 15 - 20 crankshaft revolution degrees) and on the other hand by the fact that the flowing section is the same for the analyzed cases, meaning: [3] [4]

$$
S=\frac{\pi D^{2}}{4}-\frac{\pi D_{p}^{2}}{4}=\frac{\pi}{4}\left(D^{2}-D_{p}^{2}\right)
$$

The piston-cylinder clearance reduction decreases the piston's secondary movement (1), improves the combustion chamber sealing and contributes to the durance of the segment by reduced wearing.

The piston ring secondary motions can be divided into piston ring motion in the transverse direction, piston ring rotation, ring lift, and ring twist. These types of motion result from different loads acting on the ring. Loads of this kind is inertia loads arising from the piston acceleration and deceleration, oil film damping loads, loads owing to the pressure difference across the ring, and friction loads from the sliding contact between the ring and cylinder. The piston secondary movement and the gas leakage section illustrated in Figure 2.

The flowing areas made by the gaps of piston rings were caused by the bond between regions $1-3$ and $3-5$ through the gap of the two first piston rings. If we don't consider the cylinder ovals effect, these areas will remain constant:

$$
S_{1,3}=\left(\frac{D-D_{p}}{2}\right) \cdot S_{f 1} ; \quad S_{3,5}=\left(\frac{D-D_{p}}{2}\right) \cdot S_{f_{2}}
$$

The flowing area caused by the axial clearance of the piston ring can be analyzed from the premise that the axial clearance is uniformly distributed on the bottom part of the piston (Figure 3). So, the flowing sections are:

$$
\begin{aligned}
& S_{1,2}=\pi \cdot D_{m s} \cdot x_{1} \\
& S_{2,3}=\pi \cdot D_{m s} \cdot\left(\Delta_{a_{1}}-x_{1}\right) \\
& S_{3,4}=\pi \cdot D_{m s} \cdot x_{2} \\
& S_{4,5}=\pi \cdot D_{m s} \cdot\left(\Delta_{a_{2}}-x_{2}\right)
\end{aligned}
$$




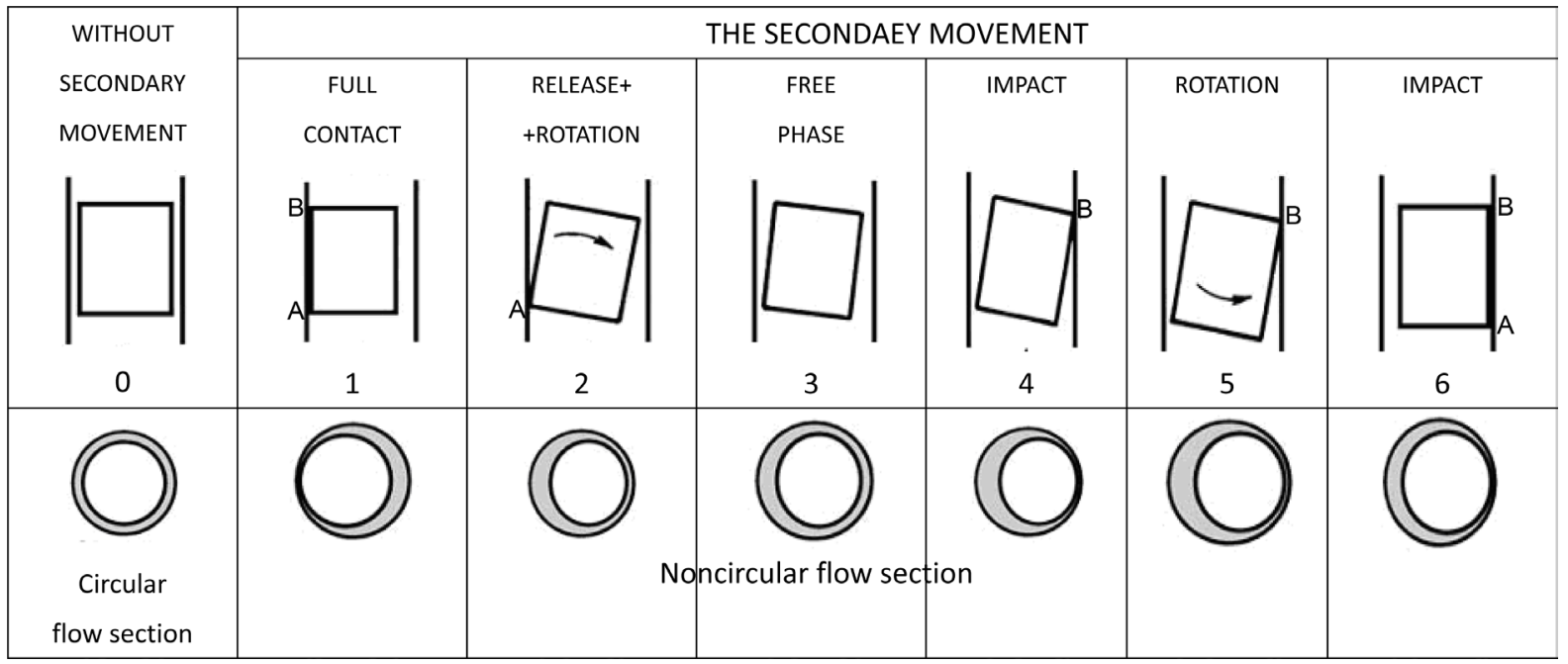

Figure 2. The piston secondary movement and the gas leakage section.

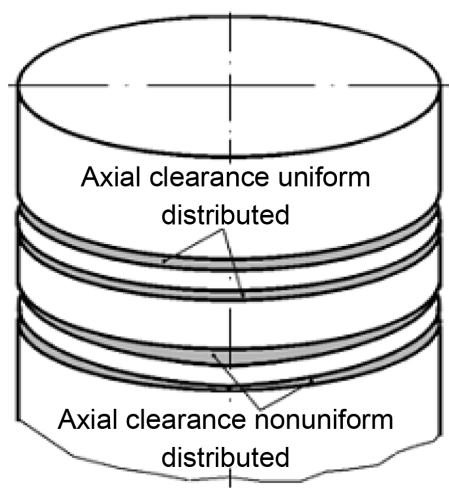

Figure 3. Axial piston rings clearance.

where:

$x$ and $x$ are the momentary axial distances between piston ring 1, piston ring 2 and the superior flanks of their grooves.

The determined flow sections made possible the study of gas leakage through the piston rings area, from the combustion chamber to the crankcase. One of the main calculated parameters was the gas pressure from the combustion chamber (based upon gas state equation) [4] [5].

\section{Calculation Results}

The used calculation model allows (based upon the general characteristics of the engine) the evaluation of gas pressure distribution along the piston rings' area, using the general characteristics of the engine. It also allows the evaluation of gas debit in these areas as well as the estimation of gas quantity that reaches the crankcase through the gaps of the piston rings and the gas quantity that comes back into the combustion chamber.

We will show some of the results obtained with the established calculation model.

A quantity of gases which returns into the combustion chamber is gathered in 
the volume of the upper part of the first segment (piston movement from TDC to BDC). This quantity of gases constitutes an important pollution source. It is better to have this quantity being reduced as for as possible, because these gases are flue gases and their existence causes an incomplete fresh air filling of the entire cylinder volume; thus worsening the combustion.

Region 1 gas volume reduction can be realized either by reducing the pistoncylinder clearance (without causing a sticking) or by approaching, as much as possible, the first segment to the superior part of the piston ring (this is limited by the increase of thermal load of the piston ring).

The piston-cylinder clearance reduction has two effects; first, the decrease of flue gases returning into the combustion chamber, and second, the decease of quantity of gases passing through the crankcase. In this way, the sealing of the combustion chamber and the durance of the piston rings will increase, too.

The diminution of the piston-cylinder clearance has also a beneficial influence on the thermal load of the piston. If the piston-cylinder clearance increases, the gas leakage toward the crankcase will increase (Figure 4) (cylinder wearing could be estimated from the measurements of gas escape quantity). The leaking amount of the gas is proportional to the area of the clearance.

A nominal clearance increase (to warm) from $100 \mu \mathrm{m}$ to $200 \mu \mathrm{m}$ causes a $60 \%$ increase in gas leakage toward the crankcase.

The bore increase makes the quantity of gas leakage increase, too.

The first piston ring position has also an influence on gas leakage. A thermal unloading of the upper part of the piston will take place if the height of the piston head is reduced.

In this way, putting the first piston as high as possible, the volume of this area is reduced, too.

If we reduce this height to $50 \%$, this would cause a $50 \%$ decrease in the gas quantity that returns into the combustion chamber (Figure 5) and would influence, in a minimal way, the gas leakage toward the crankcase (Figure 6).

But we should consider that a lower height of the piston head could cause the sticking of the first piston ring, so that the engine will break.

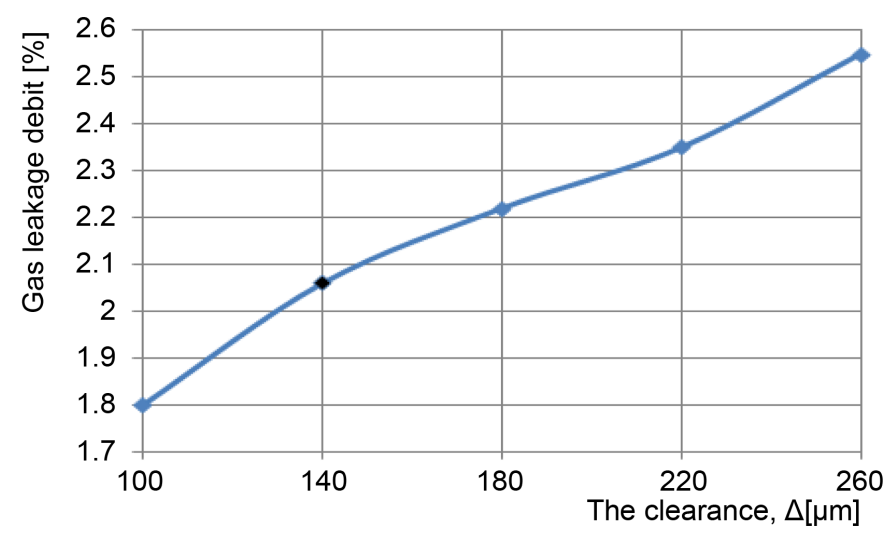

Figure 4. The bond between the quantity of gas leakage and the piston-cylinder clearance to warm. 


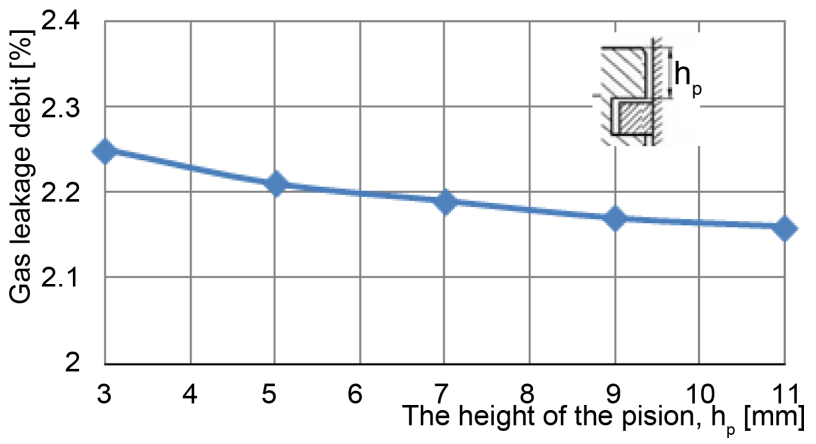

Figure 5. The influence of the first piston ring position on gas leakage.

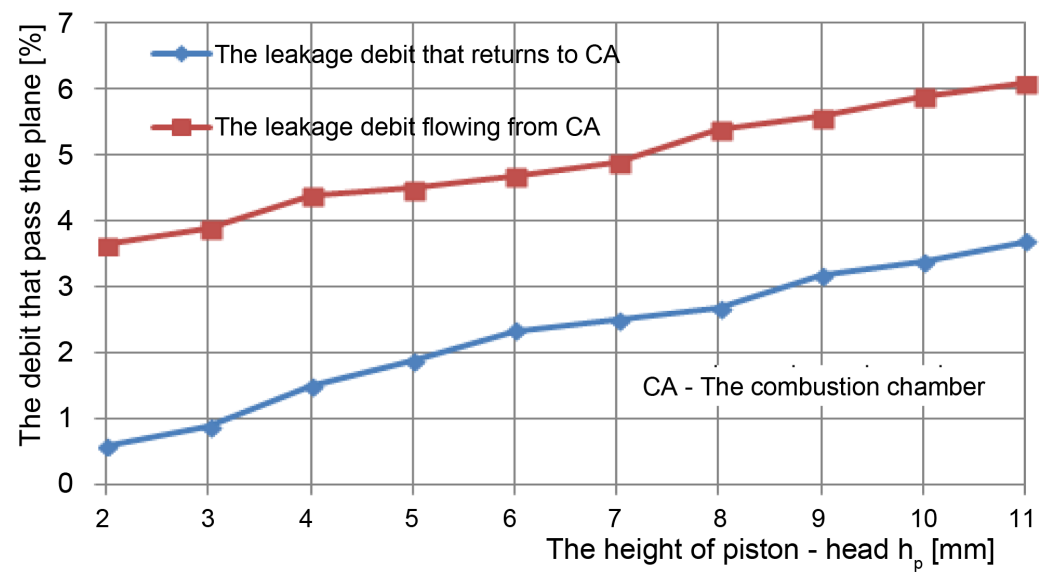

Figure 6. The quantity of gases returning into the combustion chamber depending on the first piston ring position.

Let us now to the influence of the piston rings' axial clearance. If the segments axial clearance remains within normal limits (recommended in the art), its influence on gas leakage will be minimal.

That is because the axial movement of the piston ring between the flanks of the piston ring groove lasts only a few crankshaft revolution degrees, so that gases don't have enough time to pass through the piston rings' area.

When the axial clearance is out of standard limits, its influence on gas leakage is very important. The increase in the distance between the superior flank of the piston ring groove and the superior flank of its piston ring causes the pumping so-called effect. The piston rings axial clearance in flounce over the engine speed is shown in Figure 7.

Finally, let us discuss the influence of the gap of the piston ring. Analyzing the influence first two piston rings gap on gas leakage toward the crankcase, it was established that the gas leakage from the piston rings' area increases linearly with the gap increase (simultaneously modified) of the two piston rings (Figure 8, a). The variation of the gap of the second piston ring (Figure 8, b) has a bigger influence on gas leakage toward the crankcase than that of the gap of the first piston ring (Figure 8, c). The variation of the intake valve debit coefficient does not have a significant effect on gas leakage. 


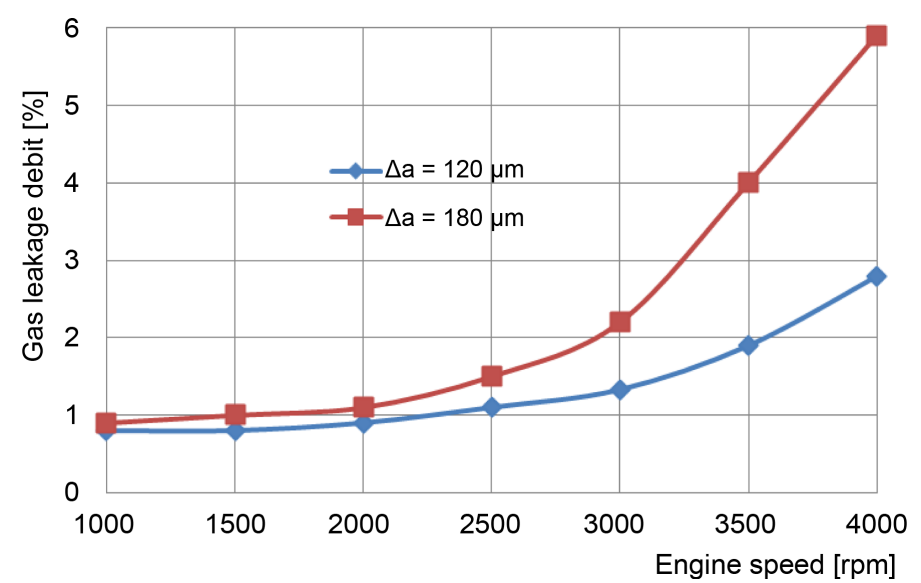

Figure 7. The piston ring axil clearance influence over the engine speed.

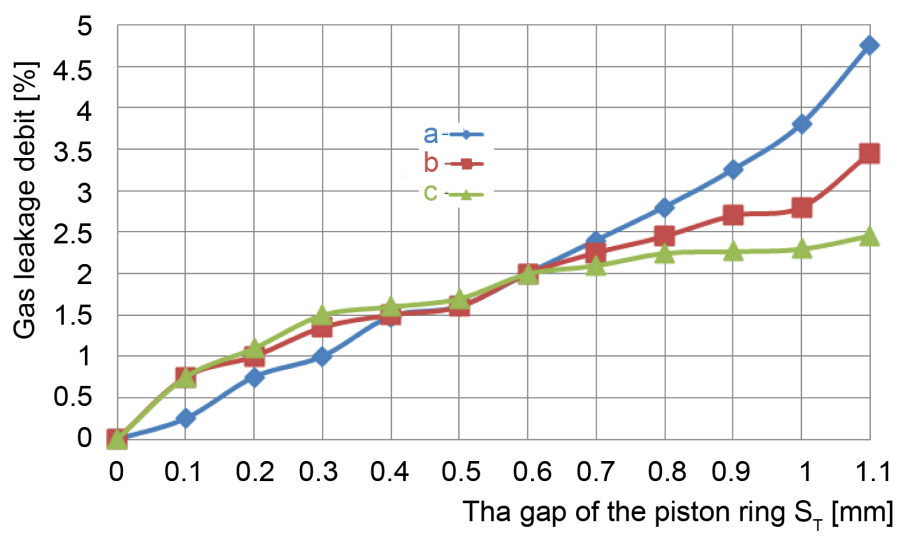

Figure 8. The influence of the gap of the piston rings on gas leakage.

\section{Conclusion}

This study allows for an evaluation of gas leakage along the piston rings' area to the crankcase. The relevant importance and influence of some geometric engine parameters on this gas leakage were shown.

\section{References}

[1] Taylor, C.M. (1998) Automobile Engine Tribology-Design Considerations for Efficiency and Durability. Wear, 221, 1-8.

[2] Heywood, J. (1988) Internal Combustion Engine Fundamentals. McGraw-Hill Education.

[3] Calculations in the Construction of Internal Combustion Engines, 2001, ISBN 9738198-17-8.

[4] Willard, W. (2004) Pulkrabek Engineering Fundamentals of the Internal Combustion Engine.

[5] Gilleaspie, T.D. (1992) Fundamentals of Vehicle Dynamics. 